\title{
Modelling of the Magnetic Characteristics of Isotropic and Anisotropic Materials for Sensor Applications
}

\author{
R. SZEWCZYK
}

\author{
Institute of Metrology and Measuring Systems \\ Warsaw University of Technology \\ św. A. Boboli 8, 02-525 Warszawa, Poland
}

and

Industrial Research Institute for Automation and Measurements

Al. Jerozolimskie 202, 02-486 Warszawa, Poland

The following paper presents the results of modelling of the magnetic characteristics of isotropic ( $\mathrm{Ni}-\mathrm{Zn}$ ferrite) and anisotropic material $\left(\mathrm{Fe}_{40} \mathrm{Ni}_{38} \mathrm{Mo}_{4} \mathrm{~B}_{18}\right.$ amorphous alloy in as quenched state), both useful for sensor applications. For the modelling an extended Jiles-Atherton model was used. Extension of the model connects model's parameter $k$, describing average energy required to break pinning site, with magnetic state of the material. Such extension of the model is reasonable from the physical point of view. Good agreement between experimental data and modelling confirms that the extended Jiles-Atherton model creates the possibility of modelling of magnetic characteristics of both isotropic and anisotropic magnetic cores.

PACS numbers: 75.60.Ej, 75.50.Gg, 75.50.Kj

\section{Introduction}

The Jiles-Atherton ( $\mathrm{J}-\mathrm{A})$ model creates the possibility of modelling the characteristics of inductive components during its operation, when magnetic cores are magnetized by unsymmetrical or transient current wave forms. It is a significant advantage, considering the fact that other models of magnetization process give only the possibility of modelling symmetrical hysteresis loops [1], which rarely has a technical application. On the other hand, the original J-A model uses the constant value of model parameters - their changes due to magnetization process are neglected. As a result, during the modelling of field dependence of magnetic characteristics, significant differences between the model and experimental results occur. This fact is the main barrier for technical application of $\mathrm{J}-\mathrm{A}$ model. 


\section{Extension of the Jiles-Atherton model}

The Jiles-Atherton ( $\mathrm{J}-\mathrm{A})$ model of magnetization process is based on the analysis of the total free energy of the magnetic material [2, 3]. This model gives the possibility of modelling of both isotropic [2] (such as ferrites), as well as anisotropic [4] magnetic materials (such as amorphous and nanocrystalline alloys). For anisotropic materials, anhysteretic magnetization $M_{\text {an }}$ is calculated as a weighted sum of anisotropic magnetization $M_{\text {aniso }}$ and isotropic magnetization $M_{\text {iso }}$ [2]. Unphysical states of the J-A model can be avoided, by the analysis of changes of irreversible magnetization $M_{\text {irr }}$ [5].

The original J-A model gives a good agreement between experimental hysteresis loop and results of the modelling, only for single hysteresis loop [6]. In the case of the family of hysteresis loops, obtained for different values of maximal magnetizing field, the quality of modelling decreases significantly. This phenomenon is caused mainly by the fact that the $\mathrm{J}-\mathrm{A}$ model parameter $k$ changes during the magnetization process [3]. Changes of parameter $k$ are caused by changes of the average energy required to break pining site [7]. For this reason, the J-A model's parameter $k$ can be connected with the magnetic state of the material (described by magnetization $M)$, by the following equation [8]:

$$
k=k_{0}+\frac{\mathrm{e}^{k_{2} \cdot\left(1-|M| / M_{\mathrm{s}}\right.}-1}{\mathrm{e}^{k_{2}}-1} \cdot\left(k_{1}-k_{0}\right)
$$

where $M_{\mathrm{s}}$ is the saturation magnetization, whereas parameters $k_{0}, k_{1}$, and $k_{2}$ describe shape of function determining $k$, as it is presented in Fig. 1.

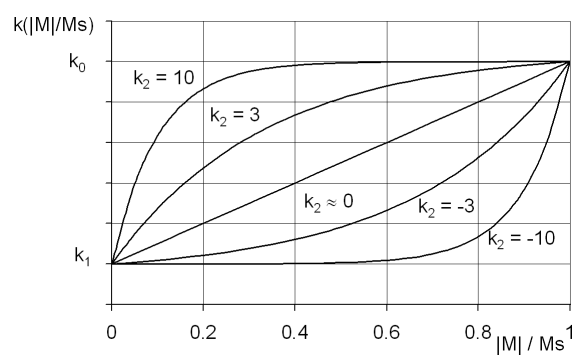

Fig. 1. Dependence of the proposed $k$ function on value of parameters $k_{0}, k_{1}$, and $k_{2}$.

\section{Results}

On the base of experimental results of measurements of quasi-static magnetization characteristics of $\mathrm{Fe}_{40} \mathrm{Ni}_{38} \mathrm{Mo}_{4} \mathrm{~B}_{18}$ amorphous alloy in as-quenched state (anisotropic material), as well as $\mathrm{Mn}_{0.51} \mathrm{Zn}_{0.44} \mathrm{Fe}_{2.05} \mathrm{O}_{4}$ high permeability ferrite (isotropic material), the $\mathrm{J}-\mathrm{A}$ model parameters were determined during the optimisation process. The target function for optimisation was based on the sum of squares of differences between modelling and experimental results. For optimisation, the evolutional strategies $(\mu+\lambda)[9]$ together with simulated annealing [10] in 
the first step, and then in the second step the gradient optimization, were applied. The calculated J-A model parameters for both materials are presented in Table, whereas the experimental and modelled hysteresis loops are shown in Fig. 2.

TABLE

The calculated J-A model's parameters.

\begin{tabular}{|c|c|c|c|c|}
\hline & & & Ferrite & Amorphous alloy \\
\hline$a$ & {$[\mathrm{~A} / \mathrm{m}]$} & quantifies domain walls density & 55.891 & 111.94 \\
\hline$k_{0}$ & {$[\mathrm{~A} / \mathrm{m}]$} & quantifies average energy & 23.405 & 382.29 \\
\hline$k_{1}$ & {$[\mathrm{~A} / \mathrm{m}]$} & required to break pining site & 106.62 & 12.569 \\
\hline$k_{2}$ & & & 9.0539 & -7.906 \\
\hline$c$ & & $\begin{array}{c}\text { describes magnetization } \\
\text { reversibility }\end{array}$ & 0.8735 & 0.4663 \\
\hline & {$[\mathrm{A} / \mathrm{m}]$} & saturation magnetization & 476824 & 294190 \\
\hline$\alpha$ & & $\begin{array}{l}\text { represents interdomain } \\
\text { coupling }\end{array}$ & $3.0833 \times 10^{-04}$ & $2.4354 \times 10^{-04}$ \\
\hline$K_{\text {an }}$ & {$\left[\mathrm{J} / \mathrm{m}^{3}\right]$} & anisotropic energy density & - & 1365.3 \\
\hline$t$ & & $\begin{array}{c}\text { perticipation of anisotropic } \\
\text { phase in the material }\end{array}$ & - & 0.7866 \\
\hline
\end{tabular}
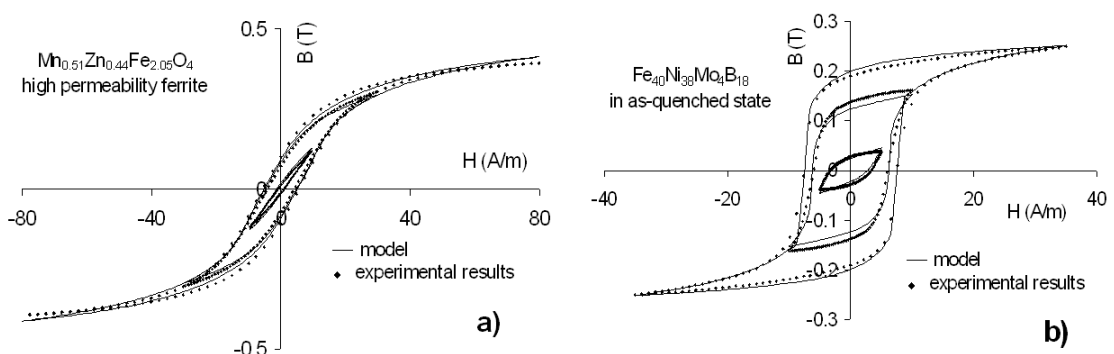

Fig. 2. Hysteresis loops obtained from extended $\mathrm{J}-\mathrm{A}$ model for: $\mathrm{Mn}_{0.51} \mathrm{Zn}_{0.44} \mathrm{Fe}_{2.05} \mathrm{O}_{4}$ high permeability ferrite, (b) $\mathrm{Fe}_{40} \mathrm{Ni}_{38} \mathrm{Mo}_{4} \mathrm{~B}_{18}$ amorphous alloy.

In Fig. 3 the results of modelling of the shape of characteristics of amplitude relative permeability $\mu_{\mathrm{a}}$ versus magnetizing field $H_{\mathrm{m}}$ are presented. Good agreement between the experimental and modelling results indicates the possibility of application of an extended $\mathrm{J}-\mathrm{A}$ model for modelling of functional characteristics of both isotropic and anisotropic magnetic materials, for different sensor applications, e.g. magnetoelastic sensors or fluxgate sensors. 


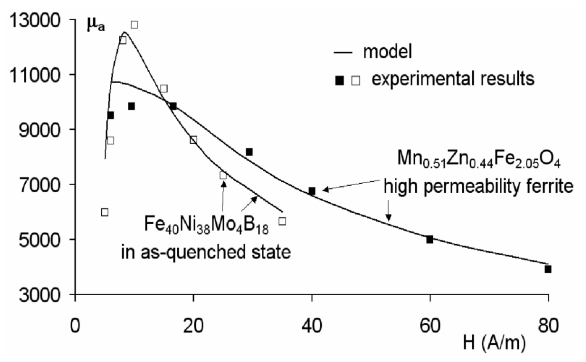

Fig. 3. Experimental (measured) and simulated magnetic relative permeability characteristics $\mu_{\mathrm{a}}(\mathrm{H})$ for: (a) $\mathrm{Fe}_{40} \mathrm{Ni}_{38} \mathrm{Mo}_{4} \mathrm{~B}_{18}$ amorphous alloy, (b) $\mathrm{Mn}_{0.51} \mathrm{Zn}_{0.44} \mathrm{Fe}_{2.05} \mathrm{O}_{4}$ high permeability ferrite.

\section{Conclusion}

Extension of the Jiles-Atherton model presented in the paper gives a better description of magnetizing process, which leads to better modelling of magnetic hysteresis loops of both isotropic and anisotropic materials. As a result, the extended J-A model better describes characteristics of magnetic cores of inductive components (especially the magnetizing field dependence of relative permeability), which is very important from the point of view of possibilities of practical applications of this model.

\section{Acknowledgments}

Calculations for the modelling were made in the Interdisciplinary Centre for Mathematical and Computational Modelling of Warsaw University, within grant G31-3. This work was partially supported by Polish Ministry of Science and Higher Education, within research grant realized in years 2005-2008.

\section{References}

[1] F. Liorzou , B. Phelps, D.L. Atherton, IEEE Trans. Magn. 36, 418 (2000).

[2] D.C. Jiles, D. Atherton, J. Magn. Magn. Mater. 61, 48 (1986).

[3] D.C. Jiles, D.L. Atherton, J. Appl. Phys. 55, 2115 (1984).

[4] A. Ramesh, D.C. Jiles, J. Roderik, IEEE Trans. Magn. 32, 4234 (1996).

[5] J. Deane, IEEE Trans. Magn. 30, 2795 (1994).

[6] R. Szewczyk, A. Bieńkowski, J. Magn. Magn. Mater. 254-255, 284 (2003).

[7] J. A. Jatau, E. Della Torre, IEEE Trans. Magn. 30, 4927 (1994).

[8] R. Szewczyk, J. Phys. D, Appl. Phys. 40, 4109 (2007).

[9] D. Lawrence, Handbook of Genetic Algorithms, Van Nostrand Reinhold, London 1991.

[10] H.P. Schwefel, Evolution and Optimum Seeking, Wiley, New York 1995. 